\title{
Golden Years? The Labor Market Effects of Caring for Grandchildren
}

The number of Americans raising grandchildren has been rising steadily. In this article, we expand what is known by focusing on the economic implications of this trend. We compile a unique data set from the Panel Study of Income Dynamics along with its Parent Identification File on 3,240 nonretired grandparent household heads and estimate the effect of taking in a grandchild on labor force participation and hours worked. We estimate models that distinguish between grandparents living alone from those only with grandchildren (skippedgeneration households) and those also with their own children (3-generation households). We find that caring for grandchildren increases labor force attachment, with grandfathers more likely to work and grandmothers working longer, if another adult is available to supervise the grandchildren.

It is well known that the structure of households in the United States has been undergoing dramatic changes. Many of these have led to important changes in children's living arrangements.

IMPAQ International, 10420 Little Patuxent Parkway, Columbia, MD 21044.

* Department of Public Policy, University of Maryland, Baltimore County, 1000 Hilltop Circle, Baltimore, MD 21250 (marcotte@umbc.edu).

**IZA, Bonn.

Key Words: caregiving, family relations, grandparent, labor force participation.
Falling rates of marriage, rising rates of divorce, and out-of-wedlock births have decreased the likelihood that children live with two parents (Cherlin \& Furstenberg, 1992; U.S. Census Bureau, 2000). Further, rising rates of substance abuse, HIV, and incarceration have limited the ability of many parents, married or single, to care for their children and have led to an increase in the likelihood that grandparents are pressed into the role of raising their grandchildren (Burton, 1992; Hayslip \& Kaminski, 2005; Minkler, 1998; Pebley \& Rudkin, 1999).

A substantial body of literature provides evidence that raising grandchildren can have negative effects on grandparents' physical and emotional health, as well as strain or limit social connections (Bachman \& Chase-Lansdale, 2005; Bower \& Myers, 1999; Lee, Colditz, Berkman, \& Kawachi, 2003; Mills, Gomez-Smith, \& De Leon, 2005; Minkler \& Fuller-Thompson, 2005). Further, supervising and providing for the daily care of grandchildren might also impose major and unexpected financial burdens (Bachman \& Chase-Lansdale; Casper \& Bryson, 1998).

In this study, we attempt to advance what is known about the economic consequences of taking in grandchildren. To do so, we examine the relationship between living with grandchildren and work. We use data from the Panel Study of Income Dynamics (PSID) and its Parent Identification File (PIF), which allow us to link younger Americans with their parents and their parents' parents. Consequently, we have constructed a nationally representative panel data set that provides information on grandparents 
who maintain their own home and on their grandchildren regardless of where the grandchildren live. These data can provide us with an understanding of the direct or resource costs that grandparents incur when deciding to take grandchildren into their homes.

\section{BACKGROUND}

To understand the costs associated with raising grandchildren, it is important to recognize the social and economic context in which grandparents agree to care for their children's children. It can be costly to raise grandchildren, yet the grandparents who do so are the most economically and socially disadvantaged. Grandparents who take in grandchildren are poor at a higher rate than the population of older Americans in general (Casper \& Bryson, 1998). Grandparents raising grandchildren are also much more likely to be African American and female. African Americans are about 1.8 times more likely than nonHispanic Whites to take grandchildren into their homes, even after controlling for a host of other factors (Cherlin \& Furstenberg, 1992; Fields, 2003; Fuller-Thompson, Minkler, \& Driver, 1997). Grandmothers account for about $77 \%$ of custodial grandparents (Hayslip \& Kaminski, 2005).

These economic differences between grandparents raising grandchildren and other grandparents give rise to our analysis. Using the PSID, our principal aim is to examine how raising grandchildren affects two primary labor market outcomes: labor force participation and the total number of hours worked for those in the labor market. We examine the relationship between the decision to take in a grandchild and the time subsequently spent in the labor market because the labor market is the principal source of income for most families and an important source of social connection and support. Part of the socioeconomic disadvantage associated with raising grandchildren may be because caring for grandchildren may limit ability to devote time to the labor market. Or it may be that caring for grandchildren requires grandparents to spend down savings or other forms of wealth. If so, caring for grandchildren may serve to reinforce social stratification.

Our analysis is shaped by what is known about the sociodemographic correlates of caring for grandchildren. That grandparents who raise their grandchildren are more likely to be female, poor, and African American is consistent with theories of intergenerational inequality and discrimination. It has been established that the socioeconomic status of one generation is correlated with that of other generations in the same family (Solon, 1992). Theories of intergenerational inequality emphasize the role of disparities in resources available to nurture children and the roles this can play in perpetuating economic differences (Becker \& Tomes, 1979; Tomes, 1981). That parents who can no longer care for their own children are more likely to come from poor families is not surprising because these young adults typically have poorer economic prospects and are at greater risk of substance abuse, violence, and incarceration. That the families most often affected by these arrangements are especially likely to be African American and those most often called on to raise grandchildren are grandmothers are consistent with a variety of theories of racial and gender discrimination (see Coleman, 1990; Feagin \& Eckberg, 1980; Loury, 1977; Merton, 1970).

Because of the importance of race and socioeconomic status in shaping decisions about caring for grandchildren and in shaping labor market outcomes, we include in our models controls for race and ethnicity, work experience, and net wealth (the difference between the value of all assets and obligations, e.g., the assessed value of a grandparent's house less outstanding mortgage balance). We also control for whether a grandparent was married or living with a spouse.

More importantly, because gender is fundamental in determining who will be called on to raise grandchildren, as well as labor market outcomes, we examine these effects separately for grandmothers and grandfathers. We also distinguish between married and unmarried grandmothers and grandfathers because individuals' determinations about market or unpaid household work are shaped by social mores, opportunity costs, and the availability of intrahousehold substitutes. For example, the social norms for older Americans likely place heavier demands on women to care for children. Or the caregiving responsibility might place strains especially on unmarried grandparents with no spouse available to help supervise or nurture grandchildren. Below, we describe our data and analytic strategy to describe differences between these groups of grandparents and to try to identify the effects of caring for grandchildren on labor market outcomes. 


\section{METHOD}

We use data from the PSID. The PSID is a nationally representative longitudinal study of U.S. families. Interviews began in 1968 with around 5,000 families. Interviews with these original families and all families that formed from them took place annually between 1968 and 1997. Since 1997, interviews have been conducted biennially. Currently, approximately 8,000 families are surveyed.

In this study, we make use of the core set of information on these families, along with supplementary data from the PIF. We use the PIF to link all children in the PSID sample with their parents. We then link those parents with their own parents, thereby identifying grandparents of children in the sample, regardless of whether they resided in the same household. Next, we restrict our sample to PSID sample members who had at least one dependent grandchild and who maintained their own households.

We make use of data collected in survey years 1994, 1997, 1999, and 2001. We pool data from each of these four survey years to construct our analytic file, which includes a total of 7,940 observations on 3,240 grandparents. The unit of analysis in our data set is the grandparent, including grandmothers and grandfathers, both married and unmarried. In the analytic sample, all observations are on noninstitutionalized biological grandparents who have at least one noninstitutionalized, live, dependent grandchild younger than 18 years old. By dependent, we mean the child is living as a dependent in someone's household (e.g., a parent, grandparent, or someone else). We focus only on biological grandparents because we anticipate the intergenerational family and financial obligations to be stronger for this group. In practice, this distinction is not important because nearly all grandparents we identify raising grandchildren are biologically related.

We believe that these data provide a key advantage over all other data sets previously examined to study the effects of taking in grandchildren. It is the first attempt to use the PSID to address the research questions pertinent to the well-being of grandparents who raise grandchildren. By making use of the features of PIF, we are able to identify a nationally representative sample of grandparents with or without grandchildren in their homes.

This data set has unique advantages over other data sets previously used to study the well-being of grandparents. The initial studies on the topic relied on administrative data sets or convenience samples, limiting the extent that conclusions could be related to the broader population. More recent studies have relied on larger, nationally representative samples but have their own limitations. For example, the Health Retirement Survey, a large-scale national survey, provides no information on persons younger than 51 years though a large fraction of grandparents are younger than this. The National Survey of Families and Households (NSFH) permits comparisons of grandparents raising grandchildren to those who are not but does not provide information on the presence of the grandchildren's parents, shown to be important in other studies. Our data set does provide information on the presence of the second generation. We describe below how we use this information.

So, the PSID provides broad and relatively detailed information about the experiences of grandparents raising grandchildren, as well as the experience of those who live separately from their grandchildren. Using these data, our first aim is to describe grandparents who care for grandchildren and compare them to those who do not. Then, to identify effects of caring for grandchildren on labor market outcomes, we estimate models of the following form:

$$
\begin{aligned}
L_{i t}= & \alpha+\beta_{1} X_{i t}+\beta_{2} G_{i t}+\beta_{3} M_{i t} \\
& +\beta_{4}\left(G_{i t} \times M_{i t}\right)+\alpha_{t}+\varepsilon_{i t},
\end{aligned}
$$

where $L_{i t}$ measures labor market behavior of grandparents, defined separately as labor force participation among nonretired grandparents, and the number of hours worked in the past 12 months, conditional on employment. We identify labor force participants from responses to a standard question on main activity in the week prior to the survey. This question is modeled after that used by the U.S. Bureau of Labor Statistics to measure unemployment monthly using the Current Population Survey. We identify respondents as labor force participants if they respond that they were currently working, actively looking for work, on maternity or sick leave, or on layoff. We identify respondents not participating in the labor force as those who were not in any of these categories and who were not retired. The measure of hours worked is the product of responses to questions about the number of weeks worked in the previous 
year and the number of hours per week usually worked.

We limit our analyses to nonretired grandparents for several reasons. First, our main interest here is on how grandparents allocate time in their working lives between paid and unpaid work. Hence, we focus on decisions to maintain a household or work for pay and how many hours to work for pay. Second, the mean age of grandparents is 60 years, with those caring for grandchildren being somewhat younger. Including the retired would have meant including those retiring early, especially among the group of particular interest. Indeed, we find that only one in five grandmothers reports being retired. Those retiring early are likely to be unrepresentative of the general population. Although this restriction precludes us from drawing conclusions about those already retired, it allows us to more directly analyze labor market patterns associated with caring for a grandchild as grandparents approach the end of their working lives.

In our models, $X_{i t}$ is a vector of individual characteristics such as race, age, and education. It also includes wealth accumulated to date (including savings, Individual Retirement Accounts, pension value, and home equity). The independent variable of particular interest is $G_{i t}$, a dummy variable equal to 1 if individual $i$ had taken in a grandchild in year $t . M_{i t}$ measures whether the grandparent is married in year $t$. The interaction term between these two variables allows us to test whether taking in grandchildren has different effects on the labor supply behavior of unmarried than married grandparents. We estimate these models separately for men and women because labor force behavior varies by gender and because care of grandchildren is likely to place different demands on grandmothers and grandfathers.

Further, we distinguish between grandparents who maintained their own homes and had livein grandchildren either with or without the grandchildren's parents in the grandparents' homes. Grandparents in the former situation, referred to as three-generation households, are likely to face a different set of demands than grandparents in the latter situation, referred to as skipped-generation households. Grandparents in three-generation households may have less dayto-day responsibility for care or may expect the child's parent(s) to contribute resources to the household. Grandparents in skipped-generation households are more likely to be responsible for both the daily care and the financial support of their grandchildren.

In all models, we estimate Huber-White standard errors, which are robust to arbitrary patterns of serial correlation. Bertrand, Duflo, and Mullainathan (2004) suggest this strategy as an effective way to draw inference on time-variant interventions in panel data with a limited number of time periods.

To attempt to control for unobserved heterogeneity between grandparents who take in grandchildren and those who do not (or between households where such arrangements are necessary and those where they are not), we employ a two-stage least squares (2SLS) estimator in which we model the decision to care for a grandchild as a function of teenage birthrates in the state, the relative leniency and generosity of state kinship foster care arrangements, and the incarceration rate for prisoners in the state. To measure teenage fertility, we make use of data on birthrates to girls between the ages of 15 and 19 years, obtained from the National Vital Statistics Reports. We obtain information on the stringency of licensing requirements for kinship care and of the generosity of reimbursement rates from the Urban Institute (Jantz, Geen, Bess, Andrews Scarcella, \& Russell, 2002; Leos-Urbel, Bess, $\&$ Geen, 1999). The policy instruments are derived from features of states' kinship foster care policies. States vary in the extent to which they encourage household members to assume guardianship for children in foster care. They do this through differences in licensing requirements for guardianship and in foster care reimbursement. We collect the information on state incarceration rates for prisoners under federal and state jurisdiction (per 100,000 residents) from the U.S. Bureau of Justice Statistics. Finally, we also use individual-level instruments including the number of dependent grandchildren and the number of adult children (separately) a grandparent has.

We expect both the state- and the individuallevel variables to provide exogenous, predictive information on the likelihood that grandparents take a grandchild into their home: Teen pregnancy rates and incarceration rates are related to the risk a grandparent would be needed to care for a grandchild; foster care policy affects the barriers and incentives faced by grandparents who might do so; the likelihood of taking in a grandchild is expected to rise with the number of grandchildren, as the number who might need such care 
rises proportionately, and the chances of taking in a grandchild should fall with the number of children a grandparent has, when other household members (aunts or uncles) could also assume care for a child. We anticipate none of these to be directly related to a grandparent's labor market behavior.

We use this 2SLS strategy to attempt to limit any effects of omitted variables rather than exploiting the panel features of our data and estimating within-grandparent effects of caring for grandchildren on labor force behavior. Doing so is necessary because of the very small amount of intertemporal variation in caregiving among grandparents.

\section{RESULTS}

For our sample drawn from the PSID, we estimate that, in any year, $7.6 \%$ of grandparents have a grandchild living in their home. The majority of these also have at least one of the grandchild's parents living with them. This estimate of $7.6 \%$ is just a bit lower than the $8 \%$ implied by the census bureau's estimate of 4.5 million grandparents raising grandchildren out of an estimated 56 million grandparents (U.S. Census Bureau, 1998, 2003, 2006). Our estimate from the PSID is lower than the $10.8 \%$ reported for the NSFH sample (Fuller-Thompson et al., 1997), but their number is an estimate of lifetime prevalence of caring for grandchildren.

In Table 1, we present descriptive statistics for the sample of grandparents from the PSID. In the first column, we present summary characteristics of the full sample. In the second and third columns, we distinguish between grandparents who are not raising grandchildren and those who are, respectively. In Columns 4 and 5, we separate grandparents with grandchildren in their homes into three- and skipped-generation households.

We provide two tests of differences in characteristics by status as a grandparent caregiver. First, we test whether each group of caregiving grandparents is significantly different from grandparents living on their own. We do this for all grandparents raising grandchildren and then separately for three-generation and skipped-generation households (i.e., we test for differences between characteristics in Columns 3 through 5 with those in Column 2). Differences in these pair-wise tests that are statistically significant at the $5 \%$ level are indicated in the relevant row and column. Then, we test whether characteristics of grandparents heading three-generation households (Column 4) are significantly different from those heading skipped-generation households (Column 5), and we report $p$ values from these tests in Column 6.

The mean age of grandparents in our sample is 60 years, and nearly $60 \%$ of living grandparents are grandmothers. In total, $71.7 \%$ of grandparents had spouses present at home. About $10 \%$ of grandparents in the sample are African American, whereas $1 \%$ are Latino. The low representation of Latinos in the sample is a legacy of the original sampling in 1968, when Latinos were a smaller portion of the population than today, as well as the decision by the PSID to drop the Latino oversample for financial reasons. The educational attainment of the sample is comparable to that of older Americans in general. Over one fifth (23.1\%) of the sample dropped out of high school compared to census-reported rates of approximately $18 \%$ of $55-64$ year olds and $26 \%$ of 65 - 74 year olds (U.S. Census Bureau, 2000). The majority completed high school, but the plurality obtained nothing beyond a high school diploma. Nearly $48 \%$ of grandparents work for pay, averaging 1,009 hours per year or nearly 25 weeks. Finally, grandparents report a mean net wealth of $\$ 380,810$.

As a first step to understand the relationship between caring for grandchildren and employment outcomes, consider differences in average characteristics between grandparents who have taken in grandchildren and those who live separately from their grandchildren. The results in Table 1 make it clear that grandparents who have taken grandchildren into their homes are younger, more likely to be female and Black, and less likely to be married. These are all consistent with census findings (U.S. Census Bureau, 2000). Further, grandparents who care for their grandchildren are somewhat less educated than other grandparents. More than one third of such grandparents are high school dropouts, and just about $6 \%$ finished college: Both are substantially different from grandparents who have not taken in grandchildren.

Given the educational and demographic differences between grandparents who do and do not care for their grandchildren, it is not surprising that their economic circumstances differ too. Grandparents with grandchildren in their homes are more likely to work and to work longer hours. Finally, the net wealth of grandparents with 


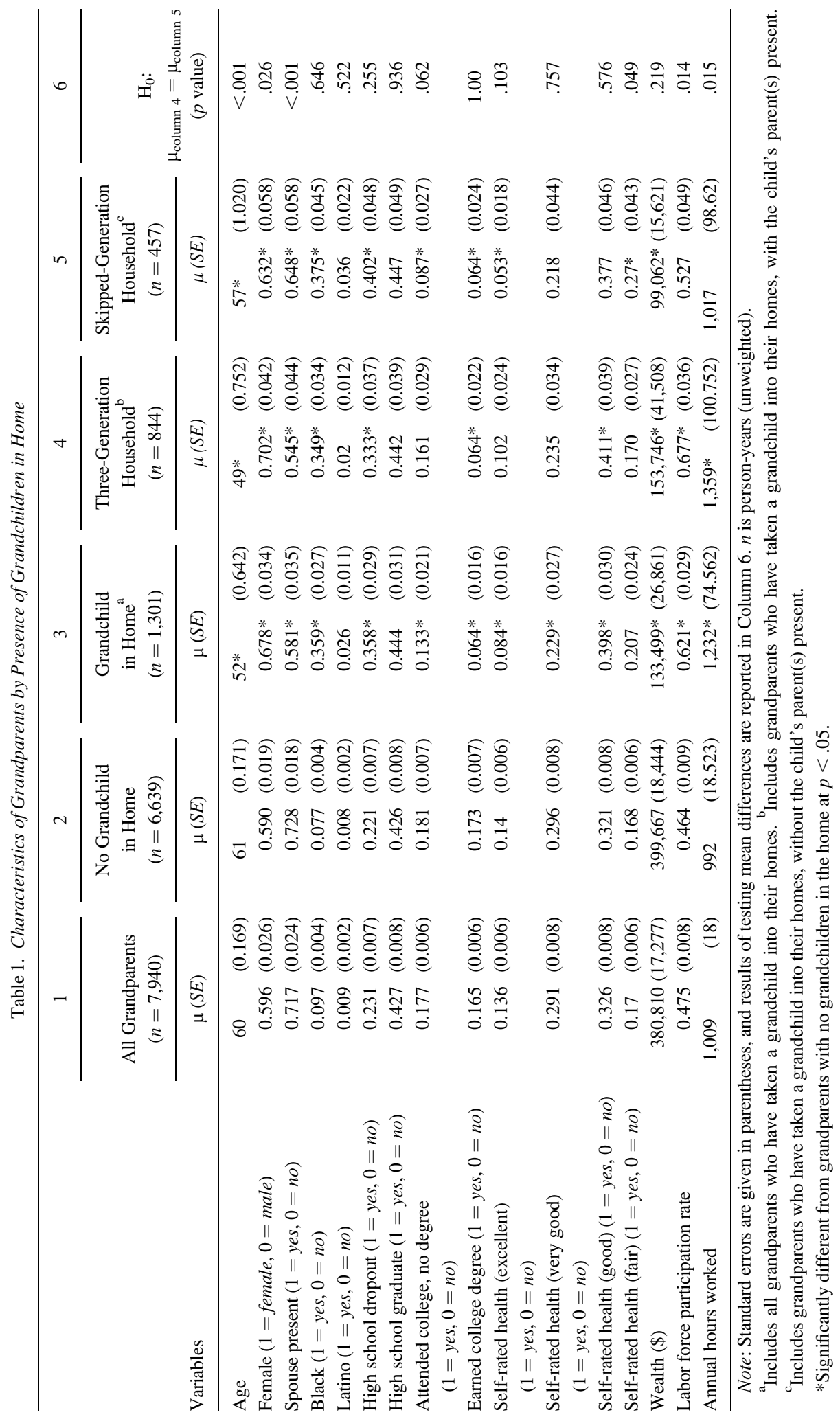


grandchildren in the home is less than one third that of other grandparents.

There are important similarities and differences between grandparents in three-generation and skipped-generation households. Both groups are much more likely than the general population of grandparents to be young, female, Black; have lower levels of education; and have accumulated less wealth. But grandparents in three-generation households are much younger than those in skipped-generation households perhaps because many of the grandchildren's parents are themselves quite young and may have never established their own households. Accordingly, grandparents in three-generation households are relatively healthy and more likely to work than are other groups of grandparents.

Next, to understand whether observed differences in labor market behaviors result from new demands placed on grandparents who decide to take a grandchild into their homes, we examine the association between intertemporal differences in grandparents' labor force behaviors and whether they accept a grandchild into their home. Using all pairs of consecutive survey years, we identify grandparents who do not have a grandchild in the home in either year and those who have a grandchild move into their home between survey years. In Table 2, we present mean changes in labor force participation rates for these groups, separately for grandmothers and grandfathers. Clearly, grandparents who have a grandchild move into their home are more likely to participate in the labor force likely because of the relative youth of these grandparents. Note also that among those who do not take in a grandchild, labor force participation rates fall at comparable rates for both grandfathers and grandmothers. A decline in the labor force participation rate is to be expected over time as more grandparents retire with each passing year.

Among those who do take in a grandchild, labor force participation rates change in different ways for grandfathers and grandmothers. Labor force participation rates decline more slowly for these grandfathers than they do for grandmothers. Indeed, the change in these grandfathers' labor force participation is not significant. One explanation for this finding may be that grandfathers in this position postpone retirement. An alternative explanation is that, because of their age, these men are less likely to retire and their labor force participation rates change less as a result.

Although grandfathers who live in households where a grandchild has moved in are the only group for which there is no intertemporal change in labor force participation, grandmothers in these households are the group that sees the largest fall of all. This result may be because grandmothers are most likely to take lead responsibility for child care and to adjust their time in the labor market accordingly. Among those who do work, there is a much more

Table 2. Changes in Labor Force Participation Rates for Grandparents Who Did/Did Not Take in a Grandchild, by Gender of Grandparent

\begin{tabular}{|c|c|c|c|}
\hline \multirow[b]{2}{*}{ Gender } & \multicolumn{3}{|c|}{ Labor Force Participation Rate } \\
\hline & $\begin{array}{l}\text { Initial Year } \\
(\text { Column 1) }\end{array}$ & $\begin{array}{l}\text { Subsequent Year } \\
\quad(\text { Column 2) }\end{array}$ & $\begin{array}{c}\mathrm{H}_{0}: \mu_{\text {column } 1}=\mu_{\text {column } 2} \\
(p \text { value })\end{array}$ \\
\hline \multicolumn{4}{|l|}{ Grandfathers, $n$ (unweighted) $=1,592$} \\
\hline $\begin{array}{l}\text { Had no grandchild in home in initial } \\
\text { or subsequent year (Row 1) }\end{array}$ & 0.536 & 0.474 & $<.0001$ \\
\hline $\begin{array}{l}\text { Took in grandchild between initial } \\
\text { and subsequent year (Row 2) }\end{array}$ & 0.878 & 0.84 & .074 \\
\hline $\mathrm{H}_{0}: \mu_{\text {row } 1}=\mu_{\text {row } 2}(p$ value $)$ & .003 & .006 & \\
\hline \multicolumn{4}{|l|}{ Grandmothers, $n$ (unweighted) $=2,276$} \\
\hline $\begin{array}{l}\text { Had no grandchild in home in initial } \\
\text { or subsequent year (Row 1) }\end{array}$ & 0.452 & 0.399 & $<.0001$ \\
\hline $\begin{array}{l}\text { Took in grandchild between initial } \\
\text { and subsequent year (Row 2) }\end{array}$ & 0.649 & 0.504 & $<.0001$ \\
\hline $\mathrm{H}_{0}: \mu_{\text {row } 1}=\mu_{\text {row } 2}(p$ value $)$ & .042 & .294 & \\
\hline
\end{tabular}


substantial decline in hours worked for grandmothers who take in a grandchild than for any other group.

We next turn our attention to the multivariate models of labor market behavior of grandparents. In Table 3, we present results of our basic models of labor force participation, for grandfathers and grandmothers separately. In each case, we first present results from models in which we do not distinguish between grandparents in threegeneration and skipped-generation households (Model 1). In Model 2, we compare grandparents in three-generation households to those with no grandchildren present (dropping those in skipped-generation households). In Model 3, we compare those in skipped-generation households to grandparents living by themselves (dropping those in three-generation households).

The results in Columns 1 and 4 suggest that, on average, both grandfathers and grandmothers who have taken a grandchild into their homes do not change their labor force behavior substantially, and this is true for both those who are married and those who are not. For both grandfathers and grandmothers however, the results presented in Columns 1 and 4 obscure important differences between grandparents in three-generation and skipped-generation households.

Grandfathers who live in three-generation households are more likely to be in the labor force than are grandfathers who live separately from their grandchildren, and this is especially true if the grandmother is not present. The labor force participation rate for unmarried grandfathers who raise grandchildren in three-generation households is about $17 \%$ higher than that for those who do not raise grandchildren. Conversely, unmarried grandfathers in skippedgeneration households are about $29 \%$ less likely to work. This result is consistent with the possibility that in skipped-generation settings, unmarried grandfathers are more pressed to provide day-to-day care for the grandchild, and doing so competes with employment demands. Unmarried grandfathers may focus more on market work when others who can supervise the child are in the household, withdrawing from the labor market when no other caregivers are available. More evidence to support this interpretation is provided by the fact that when grandmothers are in the home, this pattern for grandfathers disappears. With the benefit of a grandmother's presence, grandfathers do not change their labor force behavior.
For grandmothers, we find that the relationship between having a grandchild in the home and labor market participation differs depending on whether the second generation is present. We find no significant change in labor force participation rates of grandmothers in three-generation households, regardless of whether the grandmother is married. We find a significant increase in labor force participation rates, however, among married grandmothers in skipped-generation households. Perhaps because the grandchildren's parents are not present to contribute resources, grandmothers in such situations are more likely to seek work outside the home to help support the grandchild. That we do not observe the same response among unmarried grandmothers suggests either that the lack of a second adult in the household to watch the grandchildren limits the extent to which a grandmother can work or that grandmothers in such circumstances are especially likely to supplement income from income maintenance programs.

Table 4 provides further evidence of the burdens grandmothers shoulder. In this table, we turn our attention to establishing the relationship between taking in a grandchild and the number of hours devoted annually to work in the labor market, conditional on working at least some hours. In Columns 1 and 4, we present results from models in which the dependent variable is the number of hours a grandparent worked in the 12 months prior to the interview, conditional on being employed for pay at any time during that period. For grandfathers, there is no significant relationship between caring for grandchildren and the number of hours worked. For grandmothers, however, if a grandchild is in the house, unmarried women appear to work fewer hours. We estimate that unmarried women reduce their hours by 257 hours per year, the equivalent of reducing a 40-hour workweek to a 35-hour workweek. At the same time, we estimate that grandmothers who have a spouse in the home will work 420 hours more per year than their unmarried peers.

In the remaining columns of Table 4, we present results from models in which we compare, separately, grandparents in three-generation and skipped-generation households to grandparents living on their own. Again, it appears that taking in a grandchild had no affect on the hours grandfathers who work devote to the labor market. For grandmothers, it appears that in three-generation households, married women work substantially 


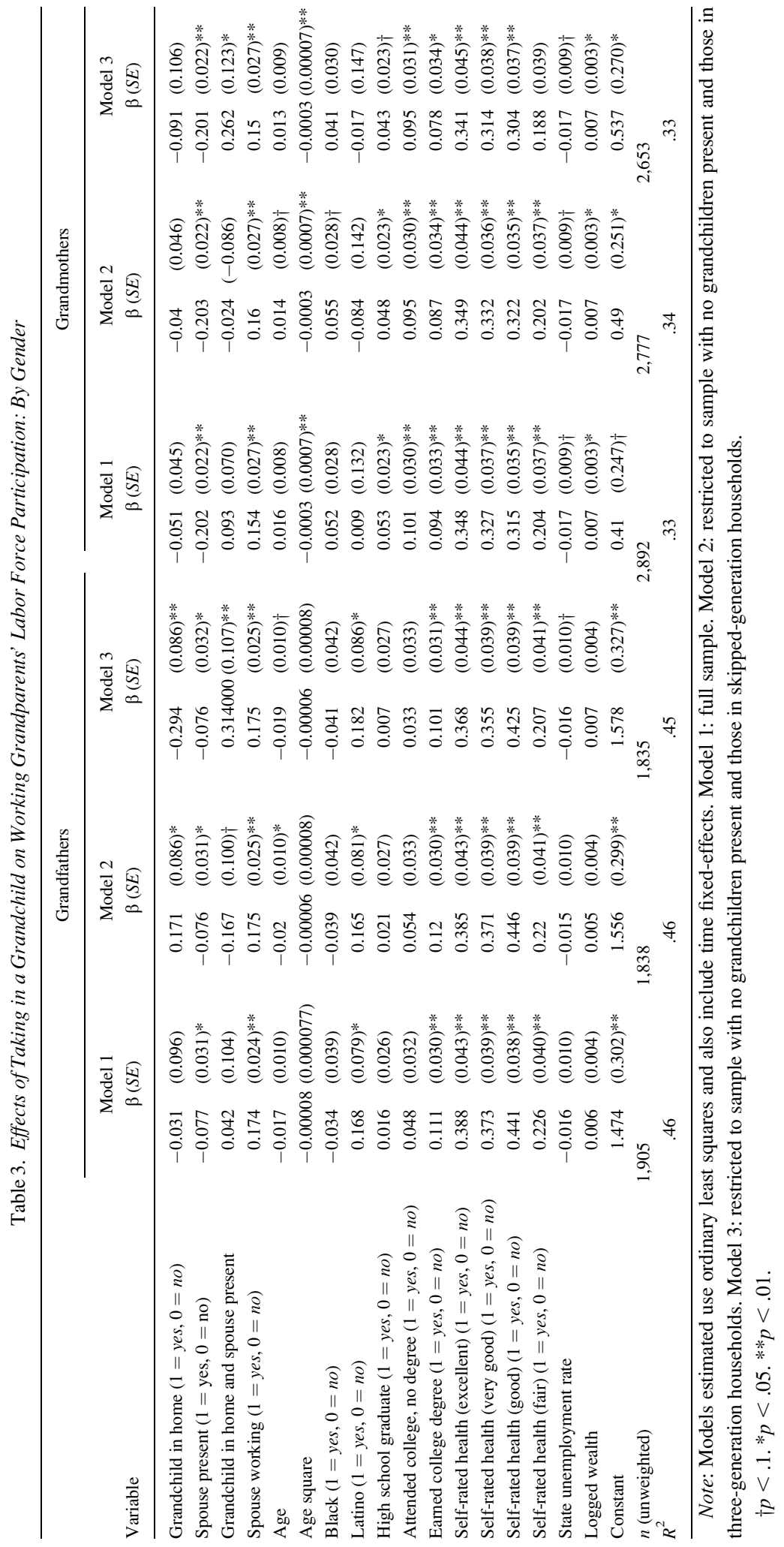




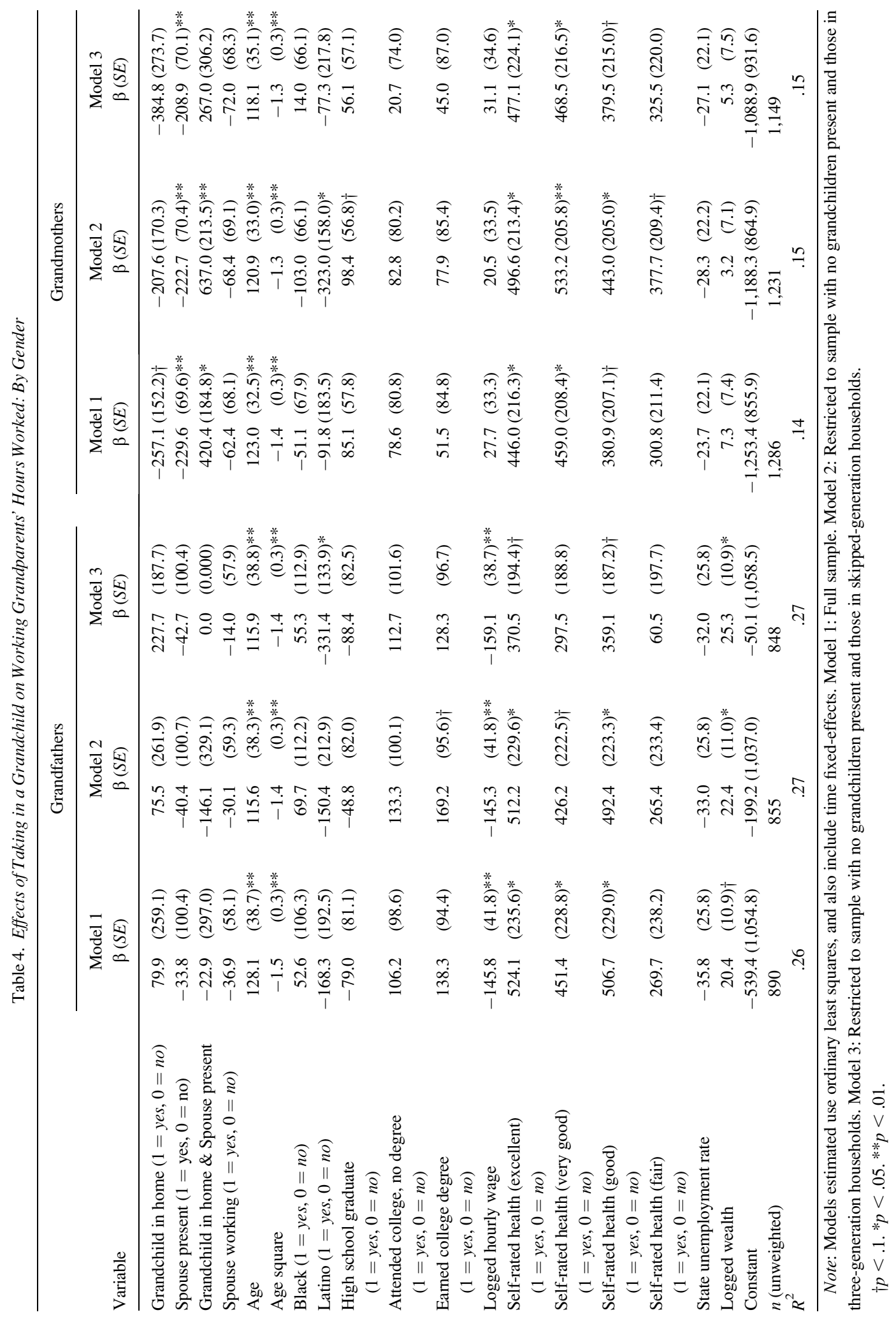


more than those who are not married. Among those in skipped-generation households, though, we do not see this increase in hours even with a spouse present. This result is to be expected because women in such households have fewer other adults to call on to supervise grandchildren.

Next, we consider the question of whether these relationships between caring for grandchildren and labor market behavior provide some insight into causal relationships. In Table 5, we summarize our 2SLS estimation of the relationship between caring for grandchildren and labor force participation and work. We present coefficients and standard errors on the key measures of grandparents' household structure, for Models 1,2 , and 3 , along with tests of the joint significance of instruments in the first stage, the $p$ value of the Hausman test of the endogeneity of caring for grandchildren (the null hypothesis is that caring for grandchildren is exogenous to decisions about labor market participation and work hours), and tests of the overidentifying restrictions (the null hypothesis is that all instruments are exogenous to labor market outcomes).

In general, the 2SLS results are consistent with the ordinary estimates presented in Tables 3 and 4 , mainly because they provide little evidence that the decision to take in a grandchild is endogenous. In the first-stage estimation, the instruments were jointly significant in all models but one. The high $p$ values reported for the Hausman test provide evidence that caring for a grandchild is not endogenous. Consequently, on the whole, the ordinary estimates are preferred.

The 2SLS results provide evidence that for grandparents in skipped-generation households, unmarried grandfathers who raise grandchildren are significantly less likely to participate in the labor force than those who live independently. For hours of work, we still find no significant effects for grandfathers. Grandmothers with a spouse present who raise grandchildren, however, work longer hours than those who do not, especially in three-generation households.

\section{DISCUSSION AND CONCLUSION}

In this article, we have used a nationally representative sample of Americans to describe the demographic and economic characteristics of grandparents who are increasingly being called upon to provide care for children with few other options. As with earlier studies, we have found that grandparents raising grandchildren are more often young, female, and Black and have lower incomes.

We also find the distinction between grandparents in three-generation households and those in skipped-generation households to be important. On average, grandparents in three-generation households are about a decade younger than grandparents living independent lives. Grandparents in skipped-generation households, however, are very similar in age to independent-living grandparents. This age difference between threeand skipped-generation grandparents explains part of the differences in health and labor force participation between the two groups.

This age difference suggests that grandparents in skipped-generation households may face particular pressure. These grandparents are older and in poorer health, limiting their ability to work, and at the same time are less likely to have members of the second generation to help with childrearing. Of course, the absence of the second generation also means that such grandparents likely rely less on the earnings of the grandchildren's parents to pay for expenses. Not surprisingly then, we find that married grandparents in skipped-generation households are especially likely to increase rates of labor force participation compared to similar grandparents living independently.

We have also found that labor force participation rates of grandparents who take in a grandchild differ in important ways from grandparents who live independently. These differences vary substantially by the presence of a spouse or second-generation parents. We find that those in skipped-generation households are more likely to adjust their behaviors in the labor force. This pattern is especially true for grandfathers who saw large increases in the rate of labor force participation if they lived in skippedgeneration households and were married. Perhaps surprisingly, grandfathers who were unmarried and in skipped-generation households participated in the labor market at a significantly lower rate. Still, it is grandmothers who exhibit the most substantial changes in labor market behavior in response to the presence of a grandchild.

This fact that grandmothers respond most substantially to the presence of a grandchild in the home, along with the substantial association of race and income with the burden of caring for grandchildren, comports with explanations that 


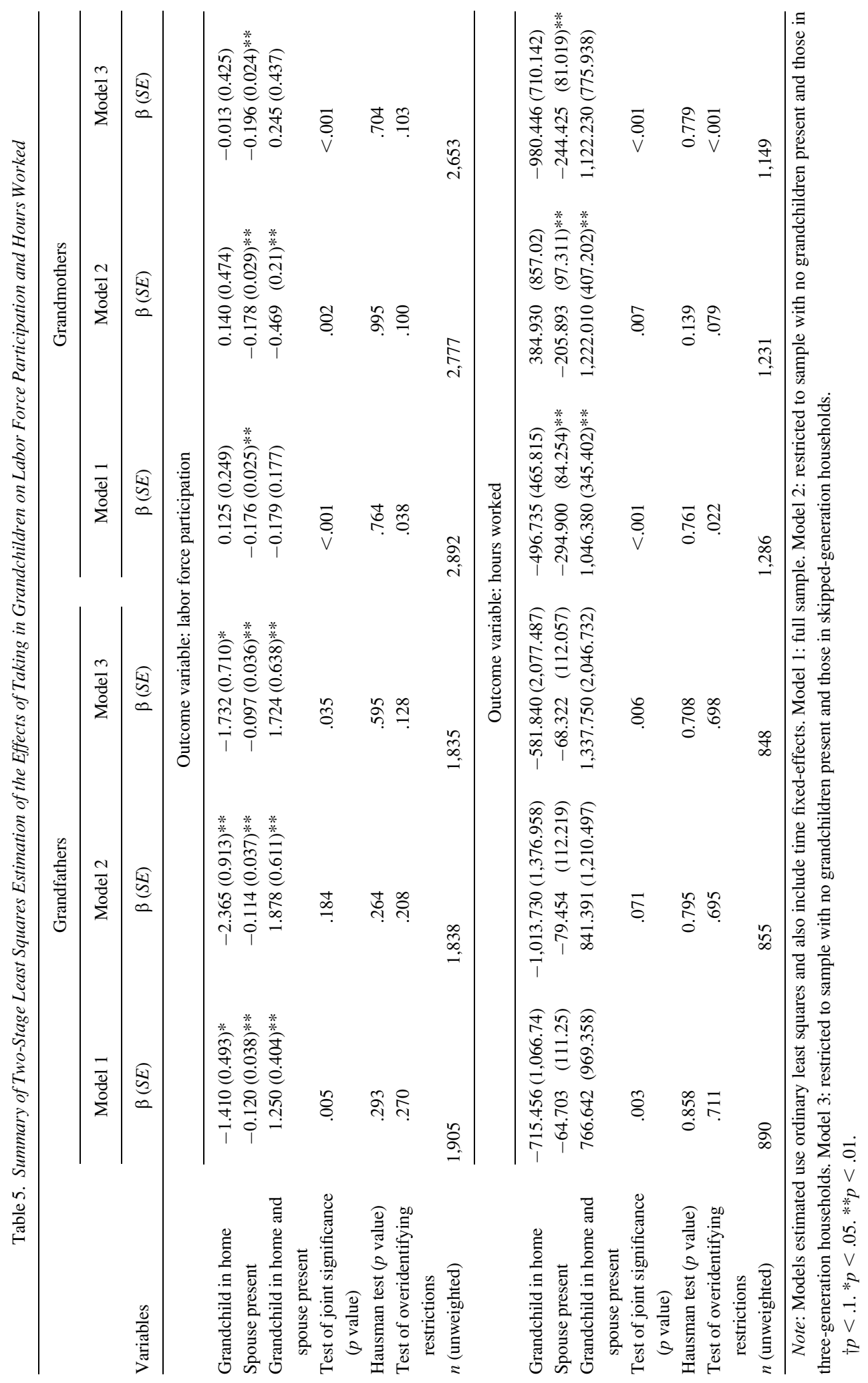


this phenomenon is rooted in inequalities and that it is gendered. The households with the least power and fewest resources are most often put in this position. And within these households, women appear to make the most substantial accommodation and sacrifice. These substantial interhousehold differences in the likelihood of raising one's grandchildren and the intrahousehold differences in subsequent labor market effects are likely related to broader social, economic, and institutional barriers faced by African Americans and to the lower value placed on market work by women, in general.

Although the PSID data provide exceptional insight into the questions raised here, these data and our study have limitations. First, though our study does much to identify the effect of caring for grandchildren on grandparents' labor market behavior, we expect that additional and unobserved characteristics of households are important determinants of the chances that grandparents need to care for grandchildren. Further efforts to better identify this relationship will be useful in providing more insight into the labor market implications of grandparents' decisions to care for their grandchildren.

An additional limitation of our study is that we do not model the decision to work, withdraw from the labor market, or retire in a dynamic context. Grandparents may move in and out of the labor force over time, in part attributable to the presence of grandchildren in the house. Raising grandchildren may even mean that grandparents may be forced to leave retirement, returning to work to fulfill new obligations to grandchildren now in their care. Such dynamics are hard to study using intermittent interviews that ask about labor force status at a point in time. We have not considered here the influence on persons already retired, perhaps in part because of the need to care for grandchildren.

Further, the PSID tells us nothing about the circumstances that brought grandchildren into the home and whether grandparents expect this to be a temporary or permanent arrangement. These dynamics and expectations would best be understood using qualitative methods to permit researchers to explore the meaning of work, retirement, and family obligations for grandparents raising grandchildren and the processes through which grandmothers and grandfathers move between them.

\section{REFERENCES}

Bachman, H. J., \& Chase-Lansdale, P. L. (2005). Custodial grandmothers' physical, mental, and economic well-being: Comparisons of primary caregivers from low-income neighborhoods. Family Relations, 54, 475 - 487.

Becker, G., \& Tomes, N. (1979). An economic theory of the distribution of income and intergenerational mobility. Journal of Political Economy, 87, 1153 - 1189 .

Bertrand, M., Duflo, E., \& Mullainathan, S. (2004). How much should we trust differences-in-differences estimates? Quarterly Journal of Economics, 119, $249-276$.

Bower, B. F., \& Myers, B. J. (1999). Grandmothers providing care for grandchildren: Consequences of various levels of caregiving. Family Relations, 48, $303-311$.

Burton, L. M. (1992). Black grandparents rearing children of drug-addicted parents: Stressors, outcomes, and social service needs. Gerontologist, 32, $744-751$.

Casper, L. M., \& Bryson, K. R. (1998). Co-resident grandparents and their grandchildren: Grandparent-maintained families (U.S. Census Bureau, Fertility and Family Statistics Branch, Population Division Working Paper No. 26). Retrieved June 15, 2005, from http://www.census.gov/population/ www/documentation/twps0026/twps0026.html

Cherlin, A. J., \& Furstenberg, F. F., Jr. (1992). The new American grandparent. Cambridge, MA: Harvard University Press.

Coleman, J. S. (1990). Foundations of social theory. Cambridge, MA: Harvard University Press.

Feagin, J. R., \& Eckberg, D. L. (1980). Discrimination: Motivation, action, effects and context. Annual Review of Sociology, 6, 1-20.

Fields, J. (2003). Children's living arrangements and characteristics: March 2002. In Current population reports. Washington, DC: U.S. Census Bureau.

Fuller-Thompson, E., Minkler, M., \& Driver, D. (1997). A profile of grandparents raising grandchildren in the United States. Gerontologist, 37, $406-411$.

Hayslip, B., Jr., \& Kaminski, P. L. (2005). Grandparents raising their grandchildren: A review of the literature and suggestions for practice. Gerontologist, 45, $262-269$.

Jantz, A., Geen, R., Bess, R., Andrews Scarcella, C., \& Russell, V. (2002). The continuing evolution of state kinship care policies. Washington, DC: The Urban Institute. 
Lee, S., Colditz, G., Berkman, L., \& Kawachi, I. (2003). Caregiving to children and grandchildren and risk of coronary heart disease in women. American Journal of Public Health, 93, 1939 1944.

Leos-Urbel, J., Bess, R., \& Geen, R. (1999). State policies for assessing and supporting kinship foster parents. Washington, DC: Urban Institute.

Loury, G. (1977). A dynamic theory of racial income differences. In P. A. Wallace \& A. M. LaMond (Eds.), Women, minorities, and employment discrimination (pp. 153 - 188). Lexington, MA: Lexington Books.

Merton, R. K. (1970). Discrimination and the American creed. In P. I. Rose (Ed.), The study of society (pp. 449 - 457). New York: Random House.

Mills, T. L., Gomez-Smith, Z., \& De Leon, J. M. (2005). Skipped generation families: Sources of psychological distress among grandmothers of grandchildren who live in homes where neither parent is present. Marriage and Family Review, 37, $191-212$.

Minkler, M. (1998). Intergenerational households headed by grandparents: Demographic and sociological contexts. In Grandparents and other relatives raising children: Background papers from Generations United's expert symposium (pp. 3 - 18). Washington, DC: Generations United.

Minkler, M., \& Fuller-Thompson, E. (2005). African American grandparents raising grandchildren: A national study using the Census 2000 American Community Survey. Journal of Gerontology: Social Sciences, 60B, S582 - S592.

Pebley, R. A., \& Rudkin, L. A. (1999). Grandparents caring for grandchildren: What do we know? Journal of Family Issues, 20, $218-242$.

Solon, G. (1992). Intergenerational income mobility in the United States. American Economic Review, $82,393-408$.

Tomes, N. (1981). The family, inheritance, and the intergenerational transmission of inequality. Journal of Political Economy, 89, 928 - 958.

U.S. Census Bureau. (1998). Life in grandma's (and/ or grandpa's) house: The grandparent's perspective (CB98-FF.10). Retrieved June 13, 2006, from http://www.census.gov/Press-Release/cb98-ff. 10.html

U.S. Census Bureau. (2000). Grandparents living with grandchildren: 2000. Retrieved June 12, 2007, from http://www.census.gov/prod/2003pubs/ c2kbr-31.pdf

U.S. Census Bureau. (2003). Grandparents Day 2003: Sept. 7 (CB03-FF.13). Retrieved June 13, 2006, from http://www.census.gov/Press-Release/ www/2003/CB03-FF13.pdf

U.S. Census Bureau. (2006). Grandparents Day 2006: Sept. 10 (CB06-FF.13). Retrieved Sep 12, 2006, from http://www.census.gov/Press-Release/ www/releases/archives/facts_for_features_special_ editions/007130.html 